\title{
EDITORIAL
}

\section{Issues in Inhalation Therapy: a new series of papers from the ADMIT Working Group}

\section{See paper by Dekhuijzen et al on page 341}

Inhalation therapy is the cornerstone of the pharmacologic treatment of patients with asthma and chronic obstructive pulmonary disease (COPD). Virtually all patients with these conditions will be treated with inhaled bronchodilators and, if indicated, inhaled corticosteroids (ICS) at some time during their lives. Inhaled therapy administered by pressurised metered dose inhalers (pMDIs) and dry powder inhaler (DPIs) has been in common use since the 1960s; DPIs can be administered by means of inhalers with one or more doses, and pMDIs can be used with or without breath actuation (in which inhalation initiates delivery) or in combination with a spacer. The advantages of inhaled therapy are clear: the drug is directed towards the target organ which reduces the dose of drug needed and limits systemic exposure. Simultaneously, there has always been awareness that inhalation of medications is relatively difficult and that it requires education and skills.

Surveys of inhaled therapy in asthma and COPD reveal patients' difficulties in handling inhalation devices, which undoubtedly contributes to suboptimal disease control. Finding hard evidence for this assumption, however, is difficult. One way of discussing and assessing the magnitude and significance of problems with inhaled medications is to identify essential issues which lead to optimal treatment of patients in daily practice.

There are three important issues when treating patients with inhaled medication: 'WHO' - i.e., what are the patient characteristics in terms of pressure and flow generation in stable and unstable conditions which determine which patient is suitable for which inhaler; 'WHERE' - i.e., where is the disease process located which one wants to target and modify; and 'HOW' - i.e., which device is the most optimal for a specific patient, taking into account a number of essential aspects of the inhalation technology of pMDIs and DPIs such as dose delivery, particle size distribution, dependence on inspiratory flow rate, and drug deposition. These considerations have consequences in the choice of a specific pMDI or DPI for patients with asthma or COPD.

A number of European experts on inhalation therapy recently joined to form the Aerosol Drug Management Improvement Team (ADMIT) - see Appendix below - and have taken on the challenge of analysing issues related to the optimal and suboptimal use of inhaled medication. In this issue of the Primary Care Respiratory Journal, we present the first paper ${ }^{1}$ in a series of papers to be published in this journal on Issues in Inhalation Therapy. The series will focus on various topics in relation to inhalation therapy, including the aims of therapy in adults and children with asthma and COPD, the characteristics of inhaled medication, their use in daily practice in stable and unstable disease, and ways to optimise inhaler use. We aim to provide the reader with an up-to-date and evidence-based review article on each subject, and each paper will contain clear recommendations for use in daily practice. Our aim is that this series of Issues in Inhaled Therapy should be of help to all healthcare professionals involved in the care of patients with astma and COPD.

\section{Conflict of interest declaration - the ADMIT Working Group}

The Aerosol Drug Management Improvement Team (ADMIT) is a consortium of European respiratory physicians with a common interest in promoting excellent delivery of inhaled drugs for asthma and COPD. It is supported by an unrestricted educational grant from MEDA AB. Members of ADMIT receive a small honorarium for attending meetings from MEDA AB and travel expenses are reimbursed.

\section{Appendix}

Members of the Aerosol Drug Management Improvement Team (ADMIT) - affiliations and individual conflict of interest declarations:

Professor Graham K Crompton (Chair)

14 Midmar Drive, Edinburgh EH10 6BU, Edinburgh, UK

Has been reimbursed by Meda $A B$ for attending conferences and/or giving presentations, and he serves as a consultant to Meda AB.

Profesor Peter J Barnes

National Heart and Lung Institute, Imperial College London, UK

Has been reimbursed for attending conferences and/or giving talks by, and has acted as a consultant for, Altana/Nycomed, AstraZeneca, Boehringer Ingelheim, GlaxoSmithKline, Novartis, Pfizer, Meda AB.

Professor Marielle Broeders

University Medical Centre Nijmegen, The Netherlands

Acts as a consultant to Meda AB.

\section{Professor Chris Corrigan}

Department of Asthma, Allergy and Respiratory Science, Guy's, Kings's and St. Thomas' School of Medicine, London, UK

Has been reimbursed for attending conferences and/or giving talks by ScheringPlough, Allergy Therapeutics, Med AB, UCB Pharma. His department has received 
research grants from GlaxoSmithKline, Novartis, ALK-Abello, Allergy Therapeutics. He has acted as a consultant for Meda AB, GlaxoSmithKline, MSD, Allergopharma, Joachim Ganzer AB.

\section{Professor Lorenzo Corbetta}

Università degli Studi di Firenze, Unità Funzionale di M edicina Respiratoria, Italy Has been reimbursed for attending conferences and/or giving talks by Meda $A B$ Boehringer Ingelheim, GlaxoSmithKline, Menarini. He acts as a consultant for Meda $A B$. His department receives unrestricted educational grants from Altana/Nycomed, AstraZeneca, Boehringer Ingelheim, GlaxoSmithKline, Novartis, Pfizer, Meda AB, Chiesi.

\section{Professor PN Richard Dekhuijzen}

Radboud University Nijmegen Medical Centre, The Netherlands

Has been reimbursed for attending conferences and/or giving talks by GlaxoSmithKline, AstraZeneca, Boehringer Ingelheim and Zambon. He serves as a consultant to GlaxoSmithKline, AstraZeneca, Merck, Meda AB, Altana Pharma, Boehringer Ingelheim and Pfizer. His department receives unrestricted research and educational grants from AstraZeneca, GlaxoSmithKline, Boehringer Ingelheim, Pfizer, Actelion, Altana and Teva and receives research grants and/or fees per patient from Novartis and Boehringer Ingelheim for performing trials.

Professor Jean Christophe Dubus

Unité de Medicine Infantile, Marseille, France

Has been reimbursed for attending conferences and/or giving talks by GlaxoSmithKline, Ivax and AstraZeneca. He has acted as a consultant for Novartis and Meda AB. His department has received research grants from Roche, Aerogen and Pari.

\section{Professor Meinhard Kneussl}

\section{Wilhelminenspital, Vienna, Austria}

Has been reimbursed for attending conferences and/or giving talks by Actelion, AOP Pfizer, AstraZeneca, GlaxoSmithKline and Boehringer Ingelheim. He also serves as a consultant to Actelion, AOP, Pfizer, Boehringer Ingelheim and Meda AB.

\section{Professor Federico Lavorini}

Università degli Studi di Firenze Unità Funzionale di M edicina Respiratoria, Italy

Has been reimbursed for attending conferences and/or giving talks by Menarini Industrie Farmaceutiche, AstraZeneca and Pfizer. He serves as a consultant to Meda $\mathrm{AB}$.

Dr Mark L Levy

Clinical Research Fellow, Division of Community Health Sciences: GP Section, University of Edinburgh, UK

Has been reimbursed for attending conferences and/or giving talks by, and has acted as a consultant for, AstraZeneca, GlaxoSmithKline, Ivax, 3M, Novartis, MSD, Altana, Meda AB, Trinity Chiesi, Boehringer Ingelheim, Ranbaxy, Innovata Biomedica and Schering Plough. He has received research grants from Ivax, Boehringer Ingelheim, GlaxoSmithKline, Schering Plough and AstraZeneca.

$\mathrm{He}$ is the Editor-in-Chief of the Primary Care Respiratory Journal, but was not involved in the editorial review of, nor the decision to publish, this article.

\section{Professor Antoine Magnan}

Université de la M éditerranée, Hôpital Ste Marguerite, Marseille, France

Has been reimbursed for attending conferences and/or giving talks by MSD, Stallergenes, AstraZeneca, Novartis, Meda AB, Boehringer Ingelheim. His department has received research grants from UCB and Novartis. He has acted as a consultant for AstraZeneca, Novartis and Meda AB.

\section{Professor Joaquin Sanchis}

Departament de Pneumologia, Hospital de la Santa Creuide Sant Pau, Universitat Autónoma de Barcelona, Spain

Has been reimbursed for attending conferences and/or giving talks by AstraZeneca and Meda AB. His department has received research grants from Novartis and
AstraZeneca. He has acted as a consultant for GlaxoSmithKlilne, AstraZeneca, Ferre and Meda AB.

Professor Jose L Viejo

Hospital General Yagüe de Burgos, Spain

Has been reimbursed for attending conferences and/or giving talks by GlaxoSmithKline, AstraZeneca, Boehringer Ingelheim, Pfizer, Zambon, MSD. He has acted as a consultant for GlaxoSmithKline, Zambon, Meda AB, Boehringer Ingelheim, Pfizer.

Professor Walter Vincken

Academisch Ziekenhuis VUB, Dienst Pneumologie, Brussels, Belgium

Acts as a consultant to Meda AB

Professor Thomas Voshaar

Krankenhaus Bethanien, M oers, Germany

Has been reimbursed for attending conferences and/or giving talks by Boehringer Ingelheim, Pfizer, Asche Chiesi, UCB, Meda AB, Altana, GlaxoSmithKline, Novartis, MSD, TEVA and $3 \mathrm{M}$. He has acted as a consultant for Boehringer Ingelheim, Pfizer, Meda $A B$ and MSD.

\section{Dr Thomas Hausen}

General Practice, Grafenstrasse 52, Essen, Germany

Acts as a consultant to Meda AB.

\section{Professor Søren Pedersen}

Professor of Paediatric Respiratory Medicine, University of Southern Denmark, Paediatric Research Unit, Kolding Hospital, Denmark

Has been reimbursed for attending conferences and/or giving talks by Altana/Nycomed, GlaxoSmithKline, Meda AB. He has received research grants from Altana/Nycomed, AstraZeneca, GlaxoSmithKline. He has acted as a consultant to Altana/Nycomed, GlaxoSmithKline, Meda AB

Dr Antonio Ramalho de Almeida

Pr. General Humberto Delgado 267, Porto, Portugal

Acts as a consultant to Meda AB.

\section{Reference}

1. Dekhuijzen PNR, Magnan A, Kneussl M on behalf of the ADMIT Working Group. The ADMIT series - Issues in Inhalation Therapy. 1) The goals of asthma treatment: can they be achieved? Prim Care Resp J 2007;16(6):341-8. doi:10.3132/pcrj.2007.00081

\section{*PN Richard Dekhuijzen}

Radboud University Nijmegen Medical Centre, The Netherlands

\section{Graham K Crompton}

(formerly) Respiratory Unit, Western General Hospital, Edinburgh, Scotland, UK

\section{*Correspondence:}

Professor PNR Dekhuijzen, Department of Pulmonary Diseases

(454), Radboud University Nijmegen Medical Centre,

P.O. Box 9101, 6500 HB Nijmegen, The Netherlands

Tel: +31-24-3614579 Fax: +31-24-3610324

E-mail: r.dekhuijzen@long.umcn.nl

5th August 2007

\section{Available online at http://ww w.thepcrj.org}

